REGARDS

SUR L'ECONOMIE ALLEMANDE

BULLETIN ECONOMIQUE DU CRAC

\section{Regards sur l'économie allemande}

Bulletin économique du CIRAC

$108 \mid 2013$

Varia

\title{
Croissance contre rigueur : une alternative illusoire
}

\section{René Lasserre}

\section{OpenEdition}

Journals

Édition électronique

URL : http://journals.openedition.org/rea/4522

DOI : $10.4000 /$ rea. 4522

ISSN : 1965-0787

Éditeur

CIRAC

Édition imprimée

Date de publication : 2 avril 2013

Pagination : 1-2

ISSN : 1156-8992

\section{Référence électronique}

René Lasserre, «Croissance contre rigueur : une alternative illusoire », Regards sur l'économie

allemande [En ligne], 108 | avril 2013, mis en ligne le 04 avril 2013, consulté le 22 septembre 2020

URL : http://journals.openedition.org/rea/4522 ; DOI : https://doi.org/10.4000/rea.4522 


\section{Croissance contre rigueur : une alternative illusoire}

Sous la pression du mécontentement croissant des populations des pays européens du Sud aux prises avec une détresse économique persistante, l'appel au relâchement de l'effort de remise en ordre des finances et des économies domestiques des pays endettés monte de toutes parts. Après les épisodes des élections italiennes et de la crise chypriote, il vient même de trouver un relais politique officiel par la voix du Président F. Hollande qui vient de tenter de le replacer au centre du débat économique européen.

Pour le président Hollande, la "bronca " méridionale est une aubaine qui vient pour ainsi dire à point nommé pour permettre au gouvernement français d'exprimer sa différence, donnant ainsi habilement le change au moment même où il se trouve en délicatesse de non-respect de ses engagements budgétaires. Au cours du dernier sommet européen du 14 mars, la France, par la voix de son Président et de son ministre des Affaires européennes, futur ministre du Budget, eut beau jeu de se prévaloir de la situation dramatique de ses voisins du Sud pour s'ériger une fois de plus en porte-parole d'une politique européenne de croissance, laquelle devrait venir enfin desserrer le carcan mortifère de la rigueur imposée à toute l'Europe par l'Allemagne.

En pleine vague d'euroscepticisme, la montée du président français aux avant-postes de ce front doctrinal répond à n'en pas douter à des fins de politique intérieure. Le Président tente ainsi d'accréditer le bienfondé d'un ajustement tempéré et étalé dans le temps d'une consolidation budgétaire devenue incontournable. Ce plaidoyer constitue cependant, au niveau européen, le signal politique manifeste d'un conflit désormais ouvert entre les deux principaux pays fondateurs et partenaires de 1'Union monétaire sur la politique économique de la zone Euro. Succédant à une série d'escarmouches antérieures et venant s'ajouter à la crise de confiance personnelle larvée du couple exécutif franco-allemand, attisée de part et d'autre par deux échéances électorales successives, cette nouvelle posture présidentielle n'est rien moins qu'anodine. Et quand bien même serait-elle d'ordre purement circonstanciel ou tactique, cette prise de distance française conforte l'incertitude qui pèse sur l'entente et la solidarité, voire sur la capacité conjointe de leadership du tandem Merkel-Hollande en cas de nouvelle crise majeure de 1'Euro.

On ne saurait certes a priori douter que le Président Hollande, en cas d'épreuve européenne décisive, ne se rallie, au même titre que ses prédécesseurs, et comme il ne cesse d'en renouveler l'engagement, à l'intérêt supérieur de l'Union. Mais est-il vraiment raisonnable et politiquement crédible que dans une situation aussi incertaine pour la cohésion de la zone Euro, et au moment où se mettent justement en place des mécanismes de gouvernance économique et financière européenne conjointe prévus dans le TSCG, de creuser des lignes de clivage dont il apparaît une fois de plus qu'elles sont davantage inspirées par le souci de ménager l'opinion domestique que par le réalisme économique? 
Tout d'abord apparait-il peu glorieux que la France tente de tirer parti des difficultés que les pays du Sud éprouvent à la suite des mesures d'ajustement drastique qu'ils ont consenties dejà depuis de longs mois sur la voie du redressement, alors qu'elle n'a pas encore réellement engagé le sien. Et tout au plus s'agit-il pour elle de desserrer l'étau de la rigueur.

Ensuite, l'affirmation selon laquelle les économies en difficulté ne pourraient sortir de la crise sans l'aide d'une politique de soutien à la croissance fondée sur une dépense publique accrue relève de l'inconséquence. Intervenant dans un contexte de déficit et d'endettement publics excessifs, la relance ne ferait alors qu'aggraver la situation et repousser les ajustements. Aussi, ceux qui s'en font les défenseurs n'hésitent-ils pas, pour contourner l'écueil, à préconiser que ces programmes de croissance fassent l'objet de financements communautaires par la voie de contributions financières solidaires ou sous la forme d'eurobonds dont la charge incomberait aux pays les plus performants. Cette voie, outre qu'elle est hautement périlleuse, ne saurait constituer une perspective politique raisonnable tant que les mécanismes actuels de garantie de la dette souveraine suffisent à peine à mettre l'Euro à l'abri des spéculations du marché, et tant que par ailleurs des règles strictes de gestion des budgets nationaux ne sont pas mises en place. Dans la situation actuelle des économies européennes, la politique de soutien à la croissance relève donc largement de l'incantation, tant ses marges de manœuvre au plan national et communautaire sont réduites. De sorte qu'en fin de compte, plaider à Bruxelles pour une politique de croissance européenne n'est guère autre chose que la forme convenue pour revendiquer un relâchement des disciplines et des responsabilités communautaires. Il n'est dès lors pas surprenant que la France excelle et se retrouve en pointe dans ce discours, sans pour autant être en mesure de convaincre.

Mais on comprend aussi pourquoi ses dirigeants actuels ont tant de mal à appréhender et à partager la logique que leurs partenaires allemands réussissent progressivement à faire prévaloir au sein de l'Union et qui consiste à retrouver des marges de croissance en réduisant les charges et à promouvoir un appareil de production plus performant. Cette politique-ci s'appuie sur l'expérience exigeante, mais aux résultats autrement plus convaincants, du changement de paradigme opéré en 2003 avec l'adoption de l'Agenda 2010. Ce vaste programme de réformes, engagé il y a dix ans, a consisté à fonder désormais la croissance sur la promotion d'une compétitivité globale de l'offre. Et ce à la fois en termes de modération des coûts du travail, de flexibilité des conditions d'emploi dans l'entreprise et d'une meilleure régulation des conditions générales de l'activité économique, notamment par l'assainissement durable des finances publiques et des régimes sociaux.

Pour réduire ce décrochage conceptuel et réévaluer les enjeux stratégiques du partenariat franco-allemand, le président Hollande serait bien inspiré de revisiter ce chapitre exceptionnel de l'histoire économique allemande récente. Il pourrait même en tirer quelques enseignements utiles pour définir enfin une stratégie claire en vue de restaurer la compétitivité de l'économie française.

René Lasserre, le 28 mars 2013 